\title{
The locus of semantic interference in the "Stroop" color-naming task
}

\author{
NANCY S. HARRISON and ELLEN BOESE \\ California State University, Hayward, California 94542
}

\begin{abstract}
In two experiments, introductory psychology students responded in two ways to three lists of 60 words printed in different colors. The lists consisted of color words and two sets of words associated with the colors (e.g., SKY, BLOOD, etc.). When the subjects responded by naming the color in which each word was printed, it took longer for the color word list than for either list of associates, i.e., the classical Stroop interference effect. The other response required the subjects to say words from one of the association lists which corresponded to the color in which each word was printed, e.g., they saw the word BLACK (or NIGHT, or COAL) printed in red ink, and had to respond by saying "blood." Using this response, it took longest for the subjects to complete the list of words which were the same as those required as responses. Color words were somewhat less difficult, and the other association words were completed most quickly. The results do not pinpoint the locus of interference, but clarify additional assumptions which must be accepted to maintain alternative hypotheses.
\end{abstract}

When a person is instructed to name as quickly as possible the color of ink in which a stimulus is printed, the latency is increased if the stimulus is a word which names a color other than the color of the ink. This interference is commonly called the Stroop effect (Stroop, 1935). A question of recurring interest concerns the locus of interference in this task.

Assume that correct performance of the colornaming task requires three processes: (1) perceive the color of the ink (input), (2) retrieve the name of the color from memory (memory retrieval), and (3) say that name (output). At which of the stages does interference from conflicting color names occur?

Hintzman, Carre, Eskridge, Owens, Shaff, and Sparks (1972), Keele (1972), and Klein (1964) have all suggested that the interference occurs because of response competition during output. Klein (1964) had his subjects name the color in which several kinds of stimulus were printed: color words, words associated with color words (e.g., SKY, BLOOD) to varying degrees, neutral words, and nonwords. He found that the degree of semantic relationship of the printed words to color words directly influenced the amount of delay. He suggested that this semantic influence could occur only subsequent to color-name retrieval, and might be caused by response competition at output.

Keele (1972) also presented color words, neutral words, and nonwords, but made two procedural changes: he used a keypress response rather than a verbal response and presented only one stimulus at a time. When he found that the color words showed

Appreciation is expressed to Stuart T. Klapp and David G. Tieman for their helpful comments during preparation of this manuscript. the usual delay relative to the other words, which did not differ from each other, he concluded that the interference from the color words occurred after color-name retrieval. He argued that the neutral words "must have contacted memory simultaneously with processing the color .... Such a discrimination of word meanings could occur only at the level of memory. Thus, it is concluded that the limitation in processing multiple sources of information is not in the memory retrieval stage but subsequent to that stage"' (p. 247).

Hintzman et al. (1972) used a mixed-list presentation in which some of the stimuli were color words, others were neutral words, and others were nonwords; of the color words, some matched the colors in which they were printed while others represented the classical nonmatching situation. The nonmatching color words lead to the usual delay relative to the neutral words and nonwords, but the matching color words actually improved performance. They argued, "If the classic Stroop condition were due primarily to interference with the ability to encode ink color, then it should make little difference whether or not a color word matched the color of the ink; interference should be produced in either case.... The present findings argue that the Stroop effect is primarily an output, rather than an input phenomenon"' (p. 459).

In view of these studies, it is not likely that interference occurs during input. However, it is not clear during which of the other two processes interference does occur.

Hock and Egeth (1970) have argued that interference in the Stroop task cannot arise during output, but must arise earlier. They required their subjects to respond "yes" or "no" depending on whether the color of the stimulus belonged to a defined set of 
target color names. They found that when the stimulus was a color word this task required more time than when the stimulus was a neutral word. Since the spoken response (yes or no) was quite different from the printed words, they suggested that the confusion does not arise solely at output, when the subject tries to formulate and say his overt response. Instead, it must occur at an earlier stage.

To recapitulate: It is not the act of reading per se which interferes with color-naming, but the semantic meaning of the word which is read. If the meaning conflicts, there is interference, regardless of the nature of the required response; if the meaning is unrelated, there is little or no effect; if the meaning is the same, there is facilitation. Where does the interference occur?

Memory retrieval only: One could assume that all the interference arises during the stage of color-name retrieval, and that response competition at output is not a source of interference. Since Hintzman et al. (1972), Keele (1972), and Klein (1964) seem to eliminate input, and Hock and Egeth seem to eliminate output, that assumption is attractive. Somehow the interfering stimuli inhibit retrieval of the color name from memory. This assumption would require that the facilitation from matching color names observed by Hintzman et al. occurs because retrieval of the color name from memory is assisted by the presence of the matching color word. Moreover, any interference from words associated with color words, such as that reported by Klein, must arise because the associate words elicit the color words as internal responses, and those internal responses interfere with color-name retrieval just as the printed color words do.

Output only: Alternatively, one could assume that all the interference arises during output. Since Hock and Egeth argued that they eliminated output, their results must be explained. That requires the additional assumption that all the interference in Hock and Egeth's results arises at a stage present in their experiment but not present in the normal color-naming task. Such a stage might well exist, consisting of comparing the ink-color name to the target set.

Both stages: Finally, one might assume that some interference from conflicting color words arises during color-naming at both color-name retrieval and output. That explanation requires no additional assumptions, but is itself more complex.

The present experiments were an attempt to further clarify the issue of the locus of interference in the Stroop color-naming task. In them, the subjects responded to three kinds of stimulus, all presented as separate lists of words: color words and two sets of words associated with the color words (e.g., SKY, BLOOD, etc.). They responded twice to each word list, making different responses on two different trials. Once they performed the usual task, and named the color in which each word was printed; it was expected that the usual color-word interference would occur relative to the associate words. The other response was more unusual: the subject was to say one of the associated words of the color in which each word was printed. For example, a subject might see the word BLACK (or COAL or NIGHT) printed in red ink, and have to respond by saying "blood." This is called the "associate-naming task." The two experiments differed from each other only in that the second incorporated some controls which were omitted in the first.

What is the relationship of these experiments with the various assumptions? There are two possible patterns of results which would be easy to interpret. One pattern would be if the color words interfered with both kinds of response more than either associate list, and the associate lists did not differ; the associate list which is being used as the response list is the same as the one which is not being used. That pattern would suggest that all the interference in the normal color-naming task occurs during color-name retrieval. In order for the color words to greatly interfere with associate-naming, the subjects must be attempting to respond by using the name of the ink color as a mediator to the associate word, but are inhibited from retrieving the ink-color name from memory by the presence of the conflicting printed color word. For example, a subject sees the word BLACK printed in red ink; he tries to retrieve the name "red" from memory to use as a mediator to the word "blood"; however, the internal response "black" interferes with that color-name retrieval process. If, instead, the subject sees the word COAL printed in red ink, the internal response "coal" interferes less with retrieval of the mediator "red."

The other relatively easily interpreted pattern would be if the color words interfered most with color-naming, but the list which interfered most with associate-naming were the list of associate words being output as responses. In the clear case, the color words and the other associate list should not differ from each other. That pattern would suggest that in both cases all the interference occurred during output, from response competition. In both cases, the list which contains the words to be output as responses is the one which interferes most; those are the words most effective as response competitors.

Intermediate results would require more complex explanations.

\section{METHOD}

\section{Materials}

Association words were obtained for six colors by asking five people to give associates to RED, YELLOW, GREEN, BROWN, BLUE, and BLACK. Two of these associates were selected by the experimenters on the basis of the associates not themselves naming 
colors and not being associated with more than one color. Then one word from each pair was assigned randomly to each of two associate lists. List A contained the words BLOOD, SUN, GRASS, CHOCOLATE, SKY, and COAL. List B contained the words TOMATO, LEMON, MONEY, COFFEE, WATER, and NIGHT.

The stimuli used in the experiment consisted of sheets of white typing paper divided into 6 rows and 10 columns. One sheet was a practice sheet. It contained an $x$ in each box, hand-printed in one of the six colors. The other three sheets were the experimental sheets. One contained the color words, arranged so that no color was printed in the color which it named. The other two sheets contained the association words of Lists $A$ and B, arranged so that no word was printed in the color with which it was associated.

Each sheet contained a different order of colors. When read across, no color appeared more than twice in sequence. Each ink color appeared 10 times on each sheet. The color words and associate words were arranged with the same restrictions.

\section{Subjects and Designs}

Experiment 1. The subjects were 33 introductory psychology students meeting a course requirement. Each subject participated in six naming tasks, with 11 subjects randomly assigned to each of three treatment orders, as follows.

For the first three trials, all subjects named the color in which each word was printed. For the last three trials, all subjects looked at the color of each word and responded by saying the corresponding word from List $\mathbf{A}$. The three word lists were presented in three different counterbalanced orders to the different groups of subjects.

Thus, there were two independent variables of interest: type of response (color-naming or associate-naming) and type of word list (color words, response-conflicting associate words, and control associate words). Both of those were varied within-subject. In addition, there was one between-subject variable, word-list order, with three levels. The dependent variable was time required to complete each stimuius sheet.

Experiment 2. The subjects were 60 introductory psychology students meeting a course requirement. Each subject participated in six naming tasks, with 5 subjects randomly assigned to each of 12 treatment groups. One-half of the subjects responded during associate-naming by saying the words on List $\mathrm{A}$; the other half said the words on List $B$. The tasks were presented in six different orders to different groups of subjects. One-half of the subjects started with three color-naming trials, then went to associatenaming; the other half used the opposite order. Three counterbalanced orders of the word lists were combined orthogonally.

Type of response and type of word list were again within-subject variables, as in Experiment 1. Thus Experiment 2 was a mixed design of a 2 by 2 by 3 (between-subject) by 2 by 3 (within-subject). The additional variabies should insure that the results are not limited to one list or response order.

\section{Procedure}

The subject and experimenter faced each other at opposite sides of a table in a soundproof chamber. First the subject received the practice list of $\times s$. When the first response was color-naming, the subject was so instructed, and told to read across the sheet as quickly as possible. When the task was associate-naming, the subject was also shown a list of six colored $\times s$ paired with either List A or List B, as appropriate. He was told to respond to each stimulus by saying the associate word of the color in which each stimulus was printed. He was allowed to practice this response by reading through the large $\times$ sheet until he said he knew the responses. This was very easy for most subjects. Then the experiment continued.

First the subject was timed on one trial through the $x$ sheet. Then he continued with the three word lists, in the appropriate order. Then he returned to the $x$ list, and received the new instructions about his response. Then there was a timed trial on the $\times$ list with the new response, followed by the three word lists. Each sheet was placed face up on the table in front of the subject. Overt errors were not systematically recorded, but virtually all were corrected by the subjects, so they would affect the time required to complete the sheet.

\section{RESULTS}

The number of seconds required for each subject to complete each of the lists using each response was recorded, and the results for each experiment were subjected to independent analyses of variance. In Experiment 1, the effects of response type, word list type, and word list order were analyzed. Neither the main effect nor any of the interactions of word list order were statistically significant, Fs $<1.00$. In Experiment 2, the effects of response type, word list type, word list order, response-word list, and response-type order were analyzed. The only significant effect involving any of the last three variables was an uninterpretable interaction of Response Type by Word List Order by Response-Word List by Response-Type Order, $F(2,240)=9.16, p<.01$.

The effects of interest were those of response type and word list type. The mean number of seconds required to complete each word list using each type of response are shown in Table 1 . The times for the practice sheets are included for comparison, but were not included in any analyses. It can be seen that the results for the two experiments were similar, although the subjects in Experiment 2 responded somewhat more slowly than those in Experiment 1.

It clearly took longer to respond by associate-naming than by color-naming: Experiment $1, F(1,150)=$ 564.40; Experiment 2, $F(1,240)=449.39$. The main effect of type of word list was also significant: Experiment 1, $F(2,150)=25.06$; Experiment 2, $F(2,240)=84.98$. And the interaction between response type and word list type was statistically significant: Experiment 1, $F(2,150)=30.03$; Experiment 2, $F(2,240)=46.03$. However, it is more appropriate to look at pairwise comparisons to see the pattern of results. To this end, a Newman-Keuls

Table 1

Mean Time (Seconds) Required to Complete Each Stimulus Sheet

\begin{tabular}{|c|c|c|c|c|}
\hline & Xs & $\begin{array}{l}\text { Color } \\
\text { Words }\end{array}$ & $\begin{array}{l}\text { Response- } \\
\text { Conflicting } \\
\text { Associ- } \\
\text { ates }\end{array}$ & $\begin{array}{l}\text { Con- } \\
\text { trol } \\
\text { Associ- } \\
\text { ates }\end{array}$ \\
\hline & \multicolumn{4}{|c|}{ Experiment 1} \\
\hline Color-Naming & 34.6 & 54.8 & 43.4 & 43.0 \\
\hline \multirow[t]{2}{*}{ Associate-Naming } & 55.8 & 68.7 & 75.0 & 64.5 \\
\hline & \multicolumn{4}{|c|}{ Experiment 2} \\
\hline Color-Naming & 39.3 & 68.0 & 50.1 & 49.9 \\
\hline Associate-Naming & 58.1 & 77.1 & 80.2 & 67.2 \\
\hline
\end{tabular}


test (Winer, 1962, p. 309) was employed. In both experiments, in color-naming, the color words took significantly longer $(\mathrm{p}<.01)$ than either associate list, and the associate lists did not differ from each other. In associate-naming, the response-conflicting associate word list required significantly longer than the color word list (Experiment $1, \mathrm{p}<.01$; Experiment $2, .01<\mathrm{p}<.05$ ), and the color words required significantly longer than the control associate word list (Experiment 1, .01 $<\mathrm{p}<.05 ;$ Experiment 2, $\mathrm{p}<.01$ ).

The treatment means suggest that the color words interfered less with associate-naming than with colornaming. In both experiments, the difference between the color words and the control associate words was greater in color-naming than in associate-naming (12 vs. $4 \mathrm{sec}$ in Experiment 1, and 18 vs. $10 \mathrm{sec}$ in Experiment 2). Of the 93 subjects in both experiments, 70 showed a greater difference between color words and control associate words in color-naming than in associate-naming, a proportion higher than would be expected by chance.

\section{DISCUSSION}

In both experiments, the color words interfered more than either associate list with color-naming. In associate-naming, the most interference was from the list of associate words being used as responses, that is, the response-conflicting associates; the color words interfered somewhat less. It can also be said that the color words interfered less with associatenaming than with color-naming. This pattern of results does not allow a clear answer about the locus of interference of conflicting color words with colornaming. However, it does increase the number of assumptions which must be accepted in order to maintain the various interpretations.

One interpretation is that all the interference of color words with color-naming occurs during retrieval of color names from memory; there is no response competition, as proposed by Hock and Egeth (1970). To maintain this position, several additional assumptions must be accepted. First, it must be assumed that interference from response-conflicting associate words with associate-naming occurs at a processing stage which is present in associate-naming but not in color-naming. Such a stage might be associate-name retrieval from memory. Second, to explain the interference of color words with associate-naming, it must be assumed that the color names are being retrieved to be used as mediators, and that the printed color words interfere with this process. Third, recall that reconciliation of this hypothesis with the findings of Klein (1964) required that words semantically related to color words interfere with color-naming by eliciting color names as internal responses which then interfere with color-name retrieval. All of this is possible, but is becoming quite complex, and therefore unattractive.

A second possibility is that all the interference in color-naming arises from response competition at the time of output. This is the interpretation offered by Hintzman et al. (1972), Keele (1972), and Klein (1964). The fact that the list which interfered most with both color-naming and associate-naming was the one containing the words being output as responses supports this interpretation. However, the color words did interfere with associate-naming; that could not have been caused by direct response competition. The output-interference hypothesis can be maintained if it is assumed that the printed color words elicited as internal responses associate words from the response-conflicting list which in turn interfered with output. For example, a person sees BLACK printed in red ink, and is supposed to say "blood." However, he thinks "coal," which interferes with his response. This hypothesis can be neither accepted nor rejected on the basis of the present data. However, when asked for their subjective opinions about whether conflicting associate words were occurring internally, the subjects said no; they felt that the color words interfered with color-name retrieval in cases when they were using the color names as mediators.

Finally, there is the third interpretation, that there are two loci of interference in color-naming, one at color-name retrieval, the other at output. In associatenaming, response-conflicting associate words interfere at output while color words interfere at colorname retrieval. In color-naming, conflicting color words interfere at both stages. In the clearest case, if strictly sequential stages were involved, interference of color words with color-naming would exactly equal the sum of the interference of color words with associate-naming plus the interference of responseconflicting associate words with associate-naming. In neither experiment was that true. In Experiment 1, there were $12 \mathrm{sec}$ of delay from using conflicting color words during color-naming as compared to the control associate list. There were $4 \mathrm{sec}$ of delay from using color words during associate-naming, and $10 \mathrm{sec}$ from using response-conflicting associate words; $12 \neq 4+10$. In Experiment 2 , the corresponding numbers were 18,10 , and $13 \mathrm{sec}$; again, $18 \neq 10+13$. Either this interpretation of there being two loci of interference in color-naming is incorrect, or the processing stages are not strictly sequential, or there is an additional locus of interference in associatenaming not present in color-naming. Such a stage could consist of retrieval of associate name from memory. 


\section{REFERENCES}

Hintzman, D. L., Carre, F. A., Eskridge, V. L., Owens, A. M., Shaff, S. S., \& Sparks, M. E. "Stroop"' effect: Input or output phenomenon? Journal of Experimental Psychology, $1972,95,458-459$.

Hock, H. S., \& EGETH, H. Verbal interference with encoding in a perceptual classification task. Journal of Experimental Psychology, 1970, 83, 299-303.

KeELE, S. W. Attention demands of memory retrieval. Journal of Experimental Psychology, 1972, 93, 245-248.

KLEIN, G. S. Semantic power measured through the interference of words with color-naming. American Journal of Psychology, 1964, 77, 576-588.

STroop, J. R. Studies of interference in serial verbal reactions. Journal of Experimental Psychology, 1935, 18, 643-662.

(Received for publication June 9, 1976; revision accepted September 24, 1976.) 